\title{
Cytoplasmic male sterility in Mimulus hybrids has pleiotropic effects on corolla and pistil traits
}

\author{
CM Barr and L Fishman \\ Division of Biological Sciences, University of Montana, Missoula, MT, USA
}

\begin{abstract}
The mechanisms underlying genetic associations have important consequences for evolutionary outcomes, but distinguishing linkage from pleiotropy is often difficult. Here, we use a fine mapping approach to determine the genetic basis of association between cytonuclear male sterility and other floral traits in Mimulus hybrids. Previous work has shown that male sterility in hybrids between Mimulus guttatus and Mimulus nasutus is due to interactions between a mitochondrial gene from $M$. guttatus and two tightly linked nuclear restorer alleles on Linkage Group 7, and that male sterility is associated with reduced corolla size. In the present study, we generated a set of nearly isogenic lines segregating for the restorer region and male sterility, but with unique flanking introgressions. Male-sterile flowers had significantly smaller
\end{abstract}

corollas, longer styles and greater stigmatic exsertion than fertile flowers. Because these effects were significant regardless of the genotypic composition of introgressions flanking the restorer region, they suggest that these floral differences are a direct byproduct of the genetic incompatibility causing anther abortion. In addition, we found a non-significant but intriguing trend for male-sterile plants to produce more seeds per flower than fertile siblings after supplemental pollination. Such pleiotropic effects may underlie the corolla dimorphism frequently observed in gynodioecious taxa and may affect selection on cytoplasmic male sterility genes when they initially arise.

Heredity (2011) 106, 886-893; doi:10.1038/hdy.2010.133; published online 19 January 2011

Keywords: gynodioecy; sexual dimorphism; CMS; genetic correlation

\section{Introduction}

In flowering plants, genetic correlations among floral traits are frequently observed both within populations and in crosses between divergent populations or species (reviewed by Ashman and Majetic, 2006). Correlations between the reproductive whorls (pistil and stamens) and corolla size metrics are of particular interest, because they mean that selection on the latter, typically mediated by pollinator attraction, may also affect fecundity or fertility, and conversely, changes in the former may affect pollinator attraction or efficiency. However, it is often not clear whether such correlations reflect a shared genetic basis (pleiotropy) or linkage disequilibrium between multiple causal loci. Given the developmental integration of floral whorls (Krizek and Fletcher, 2005), it is plausible that genetic correlations between corolla traits and reproductive organs are due to pleiotropy, a mechanism proposed even as far back as Darwin (1877) and supported by a number of experimental studies of the developmental relationship between the androecium and corolla (reviewed in Raab and Koning, 1988). Furthermore, a recent study using enforced random mating found no change in floral correlations over nine generations, which suggests that they are due to pleiotropy, and not due to linkage (Conner, 2002). However, it has also been argued that pollinator-mediated

Correspondence: Dr CM Barr, Division of Biological Sciences, 32 Campus Drive \#4824, University of Montana, Missoula, MT 59812, USA.

E-mail: cmbarr@ucdavis.edu

Received 13 February 2010; revised 26 July 2010; accepted 6 September 2010; published online 19 January 2011 selection for precise relationships between floral shape and anther location that results in optimal pollen deposition by pollinators has generated the genetic correlations between corolla and stamen size seen in many populations (for example, Conner and Sterling, 1995; Anderson and Busch, 2006).

In plants with multiple sexes, genetic correlations between reproductive organs and other floral traits frequently generate sexual dimorphism. In dioecious taxa, those with separate male and female plants, female corollas are often larger than those of males (Lloyd and Webb, 1977; Delph et al., 1996). The causes behind this relationship are not understood fully, though there is some support for the idea of selection for greater perianth size in females to protect ovaries (Delph et al., 1996). In contrast, in gynodioecious species with separate male-sterile (female) and male-fertile (hermaphrodite) plants in natural populations, female corollas are almost always smaller than those of hermaphrodites (Baker, 1948; Delph et al., 1996; Eckhart, 1999; Shykoff et al., 2003). Two hypotheses have been proposed for this relationship. The first is similar to above hypotheses for hermaphroditic taxa; that is, that developmental correlations among floral whorls lead to a direct pleiotropic effect of anther degeneration on corolla size. A handful of studies suggest a fundamental developmental relationship between the presence of the androecium and corolla size (for example, Plack 1957; Widen and Widen, 1999; Thompson et al., 2002; Schultz, 2003), although genetic demonstrations of pleiotropy between corolla and androecium are relatively rare. A second hypothesis is based on the idea of sex-dependent fitness limits, with male function in fertiles being mate-limited and seed 
production of steriles being resource-limited. This difference results in selection for greater pollinator attraction in male fertiles and thus larger flowers (Bateman, 1948). The positive effect of corolla size on pollinator visitation is well documented (for example, Bell, 1985; Ashman and Stanton, 1991; Johnson et al., 1995), but we are not aware of any direct experimental evidence that pollinator-mediated selection has generated sexual dimorphism in gynodioecious taxa.

In contrast to the androecium and corolla, correlations between the androecium and gynoecium are often weak or even negative, suggesting alternative developmental pathways and thus potentially independent evolutionary trajectories (Stanton and Preston, 1988; Conner and Via, 1993; Kudoh et al., 2001; Ashman and Williams, 2003; Schultz, 2003). In gynodioecious taxa, a necessary precondition for the maintenance of male steriles is a fitness advantage, however slight, over male fertiles (Charlesworth and Charlesworth, 1978; Frank, 1989), and in most studies, females make at least as many seeds as hermaphrodites and generally more (Van Damme and Van Delden, 1984; Manicacci et al., 1998; Frank and Barr, 2001; Barr, 2003, 2004b; Shykoff et al., 2003). Higher seed set in females is commonly attributed to some kind of reallocation of resources from pollen to seeds, avoidance of inbreeding depression or ability to better deal with ecological stress (Barr, 2003; Meagher, 2007). Pleiotropic effects of anther or pollen abortion on the gynoecium (for example, increases in ovary size or ovule number, or on stress tolerance) provide a possible mechanism for increases in the female fitness of male steriles.

Here, we investigate the mechanism of genetic associations between sexual expression and other floral/reproductive characters in interspecific Mimulus hybrids that segregate for cytoplasm-dependent male sterility (femaleness). In hybrids between outcrosser Mimulus guttatus (dam) and closely related selfer Mimulus nasutus (sire), anther sterility is caused by a chimeric mitochondrial gene (Case and Willis, 2008) and epistatically restored by two tightly linked $R f$ loci that act as a single Mendelian locus in $\mathrm{F}_{2}$ hybrids (Fishman and Willis, 2006; Barr and Fishman, 2010). This type of sexual system is called cytoplasmic male sterility (CMS) and is widespread in the plant kingdom (Budar et al., 2003). Theory argues that CMS genes, which are maternally inherited, should selfishly spread whenever the loss of male function increases female fertility. This then selects for the spread of restorers (Frank, 1989; Frank and Barr, 2001). Natural populations segregating at CMS mitochondrial and/or nuclear restorer loci will express male sterility and gynodioecy; however, fixation of both CMS and restorer(s) is the theoretically more common outcome (Charlesworth and Ganders, 1979; Burt and Trivers, 2006). Thus, crossing taxa with non-matching CMS and restorer genotypes may reveal otherwise cryptic CMS (for example, Barr, 2004a). This is the case with Mimulus, in which the Iron Mtn. M. guttatus population is fixed for the CMS mitochondrial type (Case and Willis, 2008) but entirely hermaphroditic, indicating that the restorer(s) are also fixed. Such cryptic CMS provides an opportunity to investigate the direct effects of gender on floral characters while avoiding any potential history of selection for sexual specialization in gynodioecious taxa.
Previously, we used backcross hybrids to map a major cytoplasm-dependent floral size quantitative trait locus (QTL) to the region near the nuclear restorer loci (Fishman and Willis, 2006). However, we did not have sufficient mapping resolution at that time to determine whether the reduced corolla size of male-sterile flowers was due to linkage or pleiotropy. In this study, we use nearly isogenic lines (NILs) segregating for male sterility (Barr and Fishman, 2010) to explicitly test for pleiotropic effects of CMS on corolla size (length and width) and gynoecium length. To uncouple the effects of $R f$ genotype from linked genes, we used a set of NILs with introgressions that only overlapped in the $R f$ region (that is, some lines segregated for $R f$ and genes to the right, whereas others segregated for $R f$ and genes to the left). Trait differences that are a pleiotropic effect of sterility (epistatically controlled by the $R f$ genotype) should segregate in all lines, whereas those due to linked genes on either side of the $R f$ region should only segregate in the right or left subset, respectively. Because increases in female fertility are key to the spread of CMS genes in natural populations and must be mediated by some change in the pistil and/or developing seeds, we are particularly interested in determining whether hybrid CMS has pleiotropic effects on the female whorl. To further explore the latter question, we used supplemental pollination to directly examine the effects of male sterility on female fecundity in two families.

\section{Methods}

\section{Plant materials}

To fine-map the nuclear component of cytonuclear male sterility, we previously generated lines with the M. guttatus cytoplasm (IM62 line, Iron Mountain, OR, USA), a nearly isogenic $M$. nasutus nuclear background (SF line; Sherar's Falls, OR, USA) and heterozygous introgressions for the $R f$ region on Linkage Group 7 (LG7) (Fishman and Willis, 2006; Barr and Fishman, 2010). Two independent fourth generation introgression lines were selfed to generate a large mapping population (CSBG; $N=6153$ ) segregating as $\mathrm{F}_{2}$ hybrids for the $R f$ region. These individuals were genotyped at markers across the $R f$ region and scored for male sterility to finemap the tightly linked $R f 1$ and $R f 2$ loci (Barr and Fishman, 2010).

Seven CSBG individuals with informative heterozygous introgressions were chosen for further study and selfed to generate the floral trait mapping populations used in this study (Figure 1). Two individuals (28.94 and 77.83) had introgressions including $R f 1$ and markers to the right only, two (2.24 and 18.65) had introgressions including $R f 2$ (and possibly Rf1) and markers to the left only, and three had slightly larger introgressions including $R f 1, R f 2$ and markers to the left $(15.28,46.13$ and $80.35)$. Because both $R f$ loci are dominant and independently sufficient to restore fertility, the selfed progeny of all seven lines segregate as $\mathrm{F}_{2}$ hybrids for male sterility: $\sim \frac{1}{4}$ sterile $M$. nasutus homozygotes at both loci. Rf1 and Rf2 are so close together $(<10$ recombinants in $>6000$ CSBG hybrids; Barr and Fishman, 2010) that recombination between them is unlikely in the small floral trait mapping populations. This was confirmed by genotyping of the progeny at markers flanking $R f 1$ and $R f 2$ 


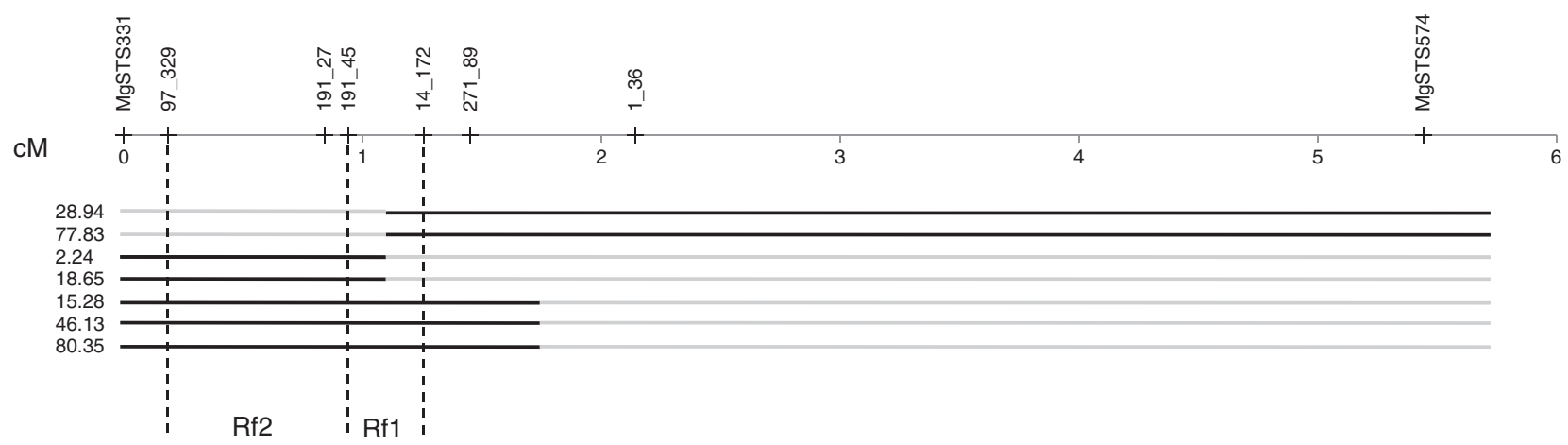

Figure 1 Map of introgressed regions of LG7 segregating in each of the experimental families. Black lines indicate heterozygous M. guttatus introgressions; gray lines indicate homozygous $M$. nasutus background. 'Rf1' and 'Rf2' are the restorer loci; a single $M$. guttatus allele at either is sufficient to restore fertility in hybrids (including these) with the M. guttatus male-sterile cytoplasmic background. LG7 (and rightward introgressions) extend further to the right; no markers have been mapped past MgSTS.331 on the left. All seven parental lines were heterozygous for at least one of the restorers, and their selfed progeny segregate for cytoplasm-dependent male sterility.

following established protocols (see Fishman and Willis, 2006; Barr and Fishman, 2010).

\section{Plant culture and phenotypic data collection}

The seven mapping populations (62-188 progeny per family) were grown under standard Mimulus culture conditions in a greenhouse at the University of Montana (Fishman et al., 2002). Families were treated as independent blocks (that is, not randomized with each other). On each plant, we assessed cytoplasm-dependent male fertility (which results in anther abortion and no pollen production) by visual examination of anthers and, when necessary, by lactophenol-aniline blue staining of the anthers to confirm no pollen production and/or anther deformity (Fishman and Willis, 2006). We measured three floral traits (corolla width, corolla length and style length; Figure 2) on a single flower on each plant. We measured corolla width on all plants and measured other floral traits on a subsample. We also calculated the style length/corolla length ratio as a measure of style exsertion on a subsample.

To investigate whether $R f$ genotype (and sterility phenotype) directly affected floral traits regardless of the surrounding introgressed genes, we first analyzed the floral trait data using a general linear model with restricted maximum likelihood (REML) estimation, with sterility and introgression type (L vs both vs R; Figure 1) as fixed effects and family (nested within introgression type) as a random effect, plus both interactions. Because our sample size within introgression types was low and it was clear that families differed in their mean flower size (presumably due to floral QTLs in either the $R f$-surrounding introgressions or unlinked introgressed regions), we then used analysis of variance, with family and sterility as fixed main effects, plus their interaction, to analyze the family-level patterns in more detail.

We used two families (46.13 and 77.83) with introgressions to the left and right, respectively, to explore associations between male sterility and maximum female fecundity in a nearly isogenic background. A subset of the selfed full-sib progeny was categorized as sterile or fertile (46.13: fertile $N=18$, sterile $N=11 ; 77.83$ : fertile $N=13$, sterile $N=14$ ) based on their first few flowers (46.13: average $=2.5$ flowers; 77.83 : average $=2.3$ flowers). Subsequent flowers (5-7 per plant) were

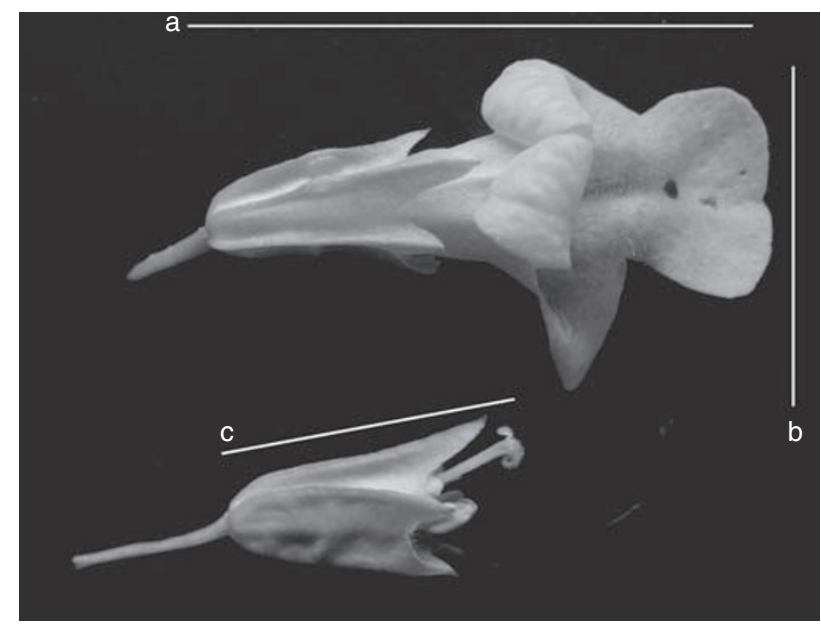

Figure 2 A male-fertile flower (top) and an extreme male-sterile flower (bottom) with upper corolla lobe absence, with floral trait measures indicated $(\mathrm{a}=$ corolla length, $\mathrm{b}=$ corolla width and $\mathrm{c}=$ style length). In some families, all male steriles resembled the bottom flower, in others all resembled fertile flowers (but generally smaller) and others varied by individual or flower.

supplemented with pollen by coating the stigmatic surface with $M$. nasutus pollen. Because of stochastic loss of some flowers, final sample sizes ranged from one to five flowers per plant (46.13: average $=4.5$ flowers / plant; 77.83: average $=4.8$ flowers/plant). Fruits were allowed to mature and seeds were collected for counting. All non-supplemented flowers were removed until seed collection to minimize variation in individual allocation to other fruits or flowers. The seed counts were analyzed using a general linear model with REML estimation with fertility, family, the fertility $\times$ family interaction and individual (random variable) nested within fertility and family. All statistical analyses were conducted using JMP 7.0 (SAS Institute, Cary, NC, USA).

\section{Results}

\section{Floral traits}

In the REML analysis at the introgression-block level, sterility phenotype had marginal or highly significant 
Table 1 Mixed model (REML) analysis of floral traits with introgression type ( $\mathrm{R}$ vs L vs both $R f$ ) and sterility as fixed effects, plus family and family $\times$ sterility effects included as random variables nested within introgression type

\begin{tabular}{|c|c|c|c|c|c|c|c|c|c|}
\hline \multirow[t]{2}{*}{ Source } & \multirow[t]{2}{*}{$D F$} & \multicolumn{2}{|c|}{$\begin{array}{l}\text { Corolla width } \\
\qquad(\mathrm{N}=978)\end{array}$} & \multicolumn{2}{|c|}{$\begin{array}{l}\text { Corolla length } \\
\qquad(\mathrm{N}=314)\end{array}$} & \multicolumn{2}{|c|}{$\begin{array}{l}\text { Style length } \\
(\mathrm{N}=314)\end{array}$} & \multicolumn{2}{|c|}{$\begin{array}{l}\text { Exsertion } \\
(\mathrm{N}=314)\end{array}$} \\
\hline & & $\mathrm{F}$ & $\mathrm{P}$ & $\mathrm{F}$ & $\mathrm{P}$ & $\mathrm{F}$ & $\mathrm{P}$ & $\mathrm{F}$ & $\mathrm{P}$ \\
\hline Introgression & 2 & 4.62 & 0.09 & 2.02 & 0.25 & 2.39 & 0.21 & 1.85 & 0.27 \\
\hline Sterility & 1 & 4.99 & 0.09 & 16.44 & 0.02 & 8.36 & 0.04 & 60.39 & $<0.002$ \\
\hline Introgression $\times$ sterility & 2 & 0.09 & 0.99 & 0.25 & 0.79 & 1.93 & 0.25 & 3.03 & 0.16 \\
\hline
\end{tabular}
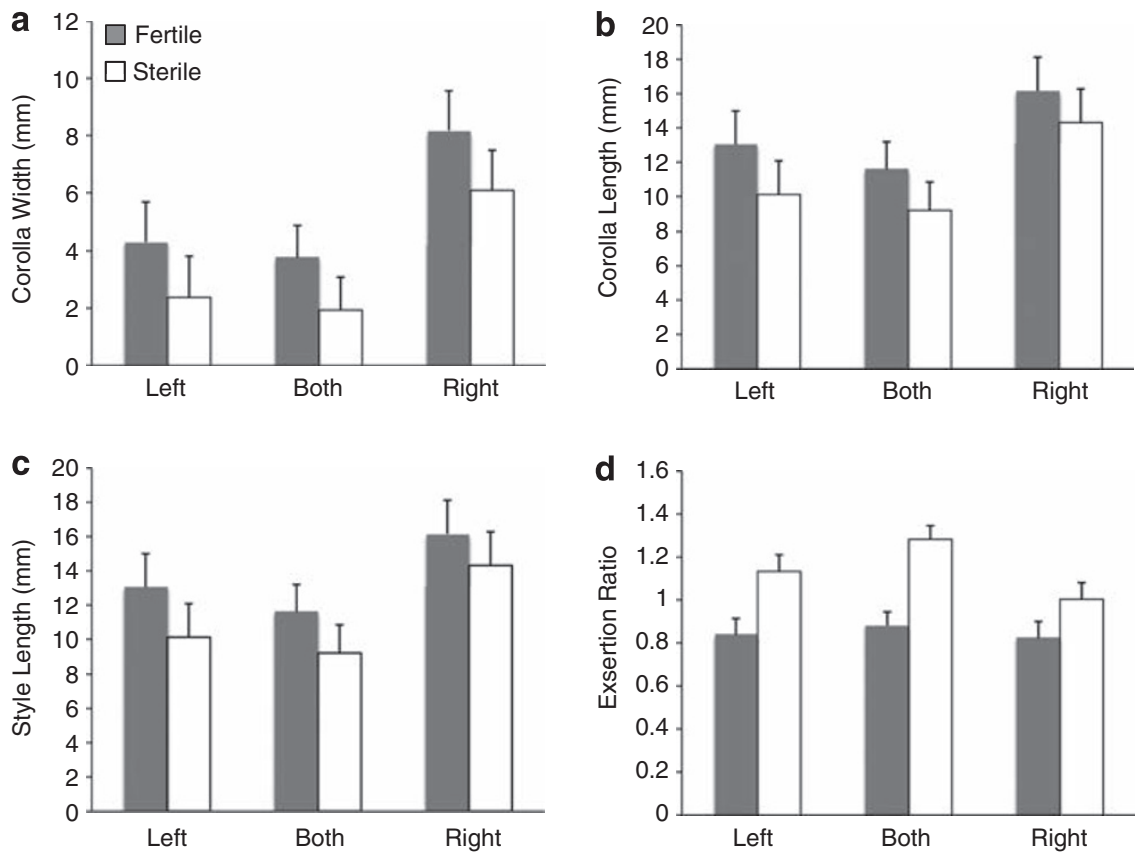

Figure 3 Least squares means ( +1 s.e.) from the REML analysis of introgression and sterility effects, showing the consistent effects of sterility across introgression type. (a) Corolla width, (b) corolla length, (c) style length and (d) stylar exsertion (corolla length/style length ratio).

effects on all four floral traits $(P=0.0015-0.09$; Table 1; Figure 3), whereas effects of introgression direction type were marginally significant for corolla width $(P=0.09)$ and not significant for other traits. The introgression $x$ sterility interaction was not significant and sterile plants, regardless of flanking region, had shorter, narrower corollas and longer styles (Figure 3). Overall, this suggests that either sterility per se (or another locus with cytoplasm-dependent expression in the Rf1-Rf2 interval) affects both flower size and the relationship between corolla and gynoecium traits.

The marginally significant introgression type effect on corolla width (and the trend for the $\mathrm{R}$ introgressions to have larger values for all size traits; Figure 3) suggests the presence of a floral size QTL elsewhere on LG7, which could be segregating or even fixed for (large) $M$. guttatus alleles. This is possible because the experimental plants had experienced two generations of selfing since the original heterozygous introgression of a large portion of LG7. Consistent with this interpretation, a moderate floral QTL was detected on the other end of LG7 in a previous study of $\mathrm{F}_{2}$ hybrids (with $M$. nasutus cytoplasm) that do not segregate for CMS expression (Fishman et al., 2002). That QTL, like the introgressed QTL to the right of the restorer region apparent in this study, had correlated effects on the three size traits, whereas male sterility causes decreases in corolla size traits but increases in style length.

To explicitly examine how family-level variation in flower size influenced the effects of male sterility, we also ran analysis of variances with family and fertility as fixed effects, plus their interaction. In this analysis, fertility remained the major source of variation, with highly significant effects on all four floral traits across families (Table 2; Figure 4). However, families also varied strongly in their mean trait values, and in their interactions with sterility (Table 2). For the primary floral traits, three, six and four families showed at least marginally (and often highly) significant differences in corolla width, corolla length and style length, respectively, in independent contrasts of least squares means (LSMs) within each family (Figure $4 \mathrm{a}-\mathrm{c}$ ). All but one family showed significant differences in stigma exsertion between sterile and fertile plants (Figure 4d), emphasizing that fertility per se caused these changes in floral allometry. For all traits, at least one family from each introgression type showed a significant effect of sterility, while controlling for background family effects, indicating 
Table 2 Analysis of variance of floral traits with sterility and family as fixed effects, for estimation of family-level effects due to genetic background

\begin{tabular}{|c|c|c|c|c|c|c|c|c|c|}
\hline \multirow[t]{2}{*}{ Source } & \multirow[t]{2}{*}{$D F$} & \multicolumn{2}{|c|}{ Corolla width } & \multicolumn{2}{|c|}{ Corolla length } & \multicolumn{2}{|c|}{ Style length } & \multicolumn{2}{|c|}{ Exsertion } \\
\hline & & $\mathrm{F}$ & $\mathrm{P}$ & $\mathrm{F}$ & $\mathrm{P}$ & $\mathrm{F}$ & $\mathrm{P}$ & $\mathrm{F}$ & $\mathrm{P}$ \\
\hline Family & 6 & 82.14 & $<0.0001$ & 91.13 & $<0.0001$ & 46.38 & $<0.0001$ & 34.52 & $<0.0001$ \\
\hline Sterility & 1 & 74.99 & $<0.0001$ & 91.26 & $<0.0001$ & 23.27 & $<0.0001$ & 451.59 & $<0.0001$ \\
\hline Family $\times$ sterility & 6 & 11.31 & $<0.0001$ & 4.01 & 0.001 & 2.87 & 0.007 & 11.29 & $<0.0001$ \\
\hline
\end{tabular}

Samples sizes are same as above.
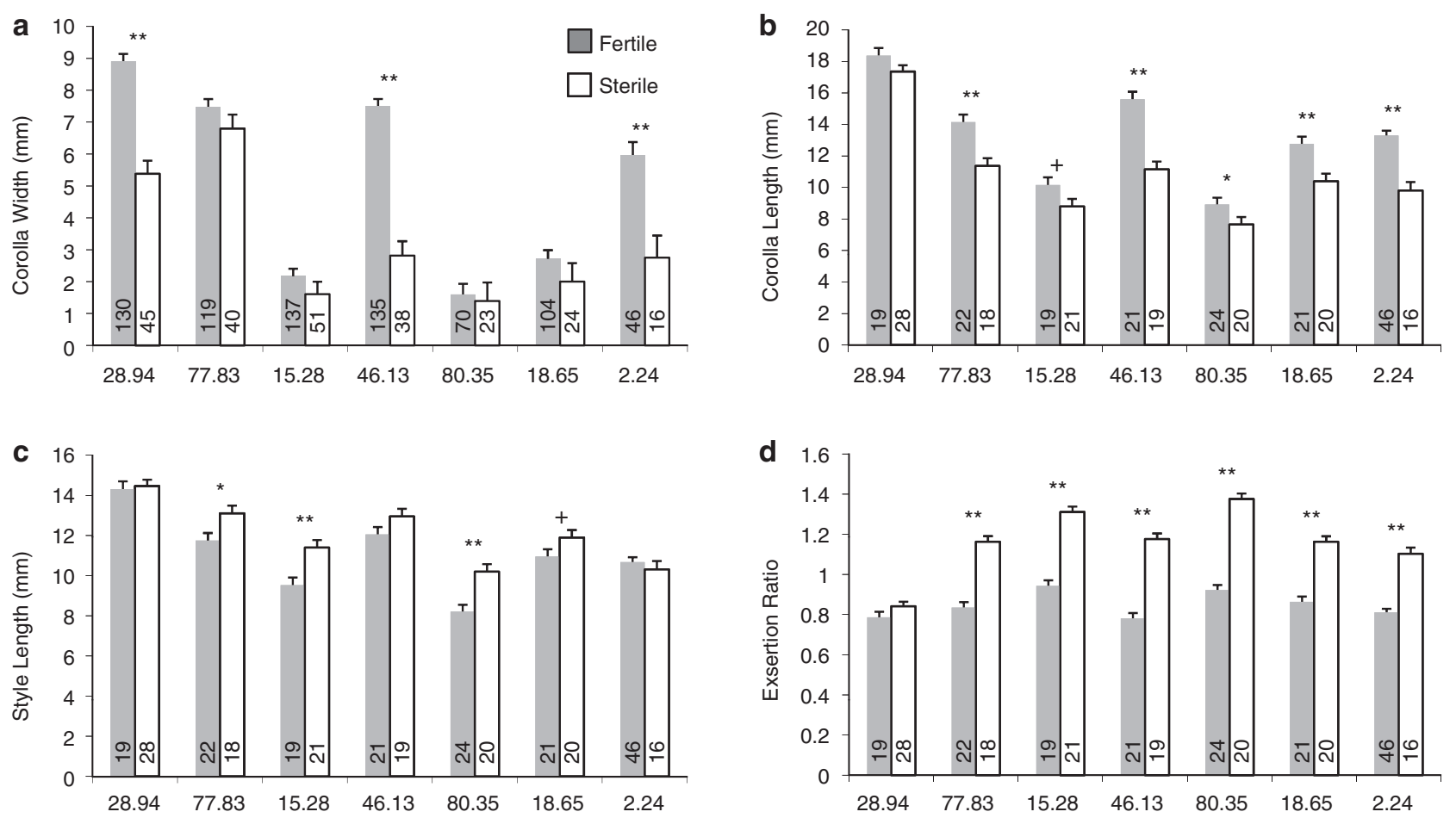

Figure 4 Least squares means ( +1 s.e.) of the family $\times$ sterility interaction from the analysis of variance of floral traits (a) corolla width, (b) corolla length, (c) style length and (d) stylar exsertion (corolla length/style length ratio). Sample sizes per family in each sterility class are at bottom of bars. ${ }^{+} P<0.10,{ }^{*} P<0.05,{ }^{* *} P<0.01$ in comparisons of LSMs within family.

that the causal locus (or loci) must be either the segregating $R f$ (controlling sterility) or another locus in the small region of line overlap.

Sterility sometimes had dramatic effects on the shape of flowers, with some (but not all) sterile flowers exhibiting no upper and highly reduced lower corolla lobes. This morphology, coupled with increases in pistil length, resulted in the exposure of the style and stigma in many sterile flowers, a trait not seen in either parental species (Figure 2, bottom). Interestingly, in one of the lines (28.94), male-sterile plants had two discrete floral morphs, a larger flower with little stigmatic exsertion, and an extreme small-flowered morph with reduced upper and lower lobes and substantial stigma exsertion. Even in this family, however, fertile flowers were larger than the larger male-sterile floral morph. In addition, in all families, male steriles often had extra stigmatic lobes. Both M. guttatus and M. nasutus normally have a twolobed stigma but in some lines, male steriles had threeand sometimes four-lobed stigmas. All of these changes are consistent with pleiotropic effects of this form of male sterility on the development of other floral parts, but also a degree of dependence on genetic background or other sources of developmental variation.

\section{Female fecundity}

On average, steriles set at least 20 more seeds than fertiles in both families (mean seed number/flowerfertiles: 202 seeds \pm 14.0 s.e.; steriles: 232 seeds \pm 17.6 s.e.). However, due to high variance in seed set among individuals, this effect of sterility was not statistically significant (Table 3). Although the two families averaged significantly different numbers of seeds ( 79 vs 355 seeds / flower for 46.13 and 77.83, respectively), the family $\times$ sterility interaction was not significant, suggesting that the trend for steriles to make more seeds than fertiles is similar among families (Table 3).

\section{Discussion}

Our results suggest that cytonuclear male sterility has pleiotropic effects on other floral traits in Mimulus 
Table 3 Mixed model (REML) analysis of seed set, with individual (nested within family) as a random effect and family (46.13 vs 77.83 ) and sterility as fixed effects

\begin{tabular}{lcrc}
\hline Source & DF & \multicolumn{2}{c}{ Seed \#/flower $(\mathrm{N}=241)$} \\
\cline { 3 - 4 } & & $\mathrm{F}$ & $\mathrm{P}$ \\
\hline Family & 1 & 149.73 & $<0.0001$ \\
Sterility & 1 & 1.75 & $<0.1919$ \\
Family $\times$ sterility & 1 & 0.17 & $<0.6814$ \\
\hline
\end{tabular}

hybrids, with implications for understanding the evolutionary history of CMS in both interspecific hybrids and gynodioecious taxa. Male-sterile flowers had smaller corollas, longer styles and greater stigmatic exsertion than fertile flowers (Tables 1 and 2; Figures 3 and 4). As evidenced by the up to sixfold variation in mean corolla width among families (Figure 4), corolla size was determined by multiple factors even in our NILs. However, because sterility effects were consistent regardless of the genotypic composition of introgressions flanking the restorer region, pleiotropy appears to underlie the floral trait differences between sterile and fertile genotypes. If similar pleiotropic effects accompany CMS when it arises in natural populations, selection for or against sterility will necessarily affect other traits and vice versa. They may also provide an explanation for the corolla dimorphism frequently observed between hermaphrodites and females in gynodioecious taxa. In the two families tested, we found that male-sterile plants produced $\sim 20$ more seeds per flower than fertile siblings after supplemental pollination, but this trend was not statistically significant. However, in combination with a highly significant effect of male sterility on pistil size, this finding suggests that the selfish spread of malesterilizing mitochondria via pleiotropic female fitness gains is mechanistically plausible.

Pleiotropic effects of male sterility on corolla and style size in hybrids with CMS are consistent with the developmental correlation hypothesis for gynodioecy proposed by Darwin (1877) and others (Thompson et al., 2002; Schultz, 2003), and may be a downstream effect of anther degeneration. The development of corolla traits is often mediated by hormones, particularly gibberellins, provided by developing anthers (Raab and Koning, 1988). Gibberellins are important for cell elongation and the tapetum, a layer of cells in the anther surrounding the microspores, is the site of some of the highest expression of gibberellic acid synthesis genes (for example, Kaneko et al., 2003). Tapetal degeneration and pollen abortion, a characteristic of CMS in crop systems (Hanson and Bentolila, 2004) is prevented by pentatricopeptide (PPR) restorers, such as those identified in this Mimulus system (Barr and Fishman, 2010). This provides a simple mechanism for effects of restorer segregation (in a CMS background) on floral morphology in our hybrids, and may also contribute to the common observation that male-sterile (female) flowers are smaller in many gynodioecious taxa (Baker, 1948; Delph et al., 1996; Eckhart, 1999). Our results are also consistent with observations in crop CMS hybrids, in which cytoplasmic type has a variety of effects on floral morphology in addition to fertility (Zubko et al., 2003; Hanson and Bentolila, 2004). However, we note that selection for increased allocation to corollas via male fitness in hermaphrodites (for example, Bell, 1985; Ashman and Stanton, 1991; Johnson et al., 1995) could accentuate initial differences due to direct developmental effects.

It is briefly worth considering the potential consequences of pleiotropic reduction in floral size on pollinator visitation during the initial spread of a CMS mutation. We cannot be sure that such effects would occur in a purely M. guttatus background, but effects of sterility on corolla size were visible in the $F_{2}$ and backcross populations used to map the $R f$ region to LG7 (Fishman and Willis, 2006), suggesting that they are not unique to an all $M$. nasutus background. Interestingly, segregating variation in those generations was entirely quantitative, with none of the extreme upper corolla loss observed in the current NIL-based mapping populations. (M. nasutus is facultatively cleistogamous (Diaz and MacNair, 1998) and its corollas change allometry below some threshold size; this developmental feature may interact with the effects of sterility.) Therefore, any corolla effects of a newly arisen (unretired) CMS mutation in $M$. guttatus would likely be less extreme and not involve upper corolla lobe loss. In addition, we have found that positive associations between corolla size and seed set in the field are not mediated by pollinator attraction despite pollen limitation of female fertility (Fishman and Willis, 2008). Therefore, it is not possible to conclude that changes in flower size due to CMS pleiotropy, which are within the range of natural variation in flower size within $M$. guttatus populations (Fishman and Willis, 2008), would reduce female fitness through pollinator attraction.

The positive pleiotropic effect of CMS on style length in our hybrids presents a possible explanation for gynodioecious taxa, in which male steriles (females) also have longer pistils than male fertiles (hermaphrodites) (Schultz, 2003; Golonka et al., 2005), and is consistent with theory suggesting that CMS spreads selfishly via positive effects on female function. Maternally inherited (for example, mitochondrial) genes which cause male sterility should readily spread toward fixation if they cause even marginal increases in female fitness (for example, Frank, 1989). Consistent with this theory, male steriles often have higher seed set than fertiles in gynodioecious taxa (Van Damme and Van Delden, 1984; Frank, 1989; Manicacci et al., 1998; Frank and Barr, 2001; Barr, 2003; Shykoff et al., 2003; Barr 2004b). One explanation for this difference is reallocation of resources from pollen to seeds (Atlan et al., 1992; Ashman, 1994). However, it is not clear whether this pattern reflects direct effects of male sterility or the later accumulation of alleles with sex-specific effects linked to the restorer or nuclear sex-determining locus. We did not have power to detect significant effects of male sterility on seed set itself, but both our style length data and the observed trend for sterile plants to set more seeds are consistent with positive effects on female function being an intrinsic property of CMS mutations (at least those that spread to fixation within populations).

This interpretation is further supported if we consider the pleiotropic effects of CMS with the genetic architecture of floral traits in non-CMS Mimulus hybrids. In previous studies of $M$. nasutus $\times M$. guttatus hybrids, most floral QTLs affected pistil and stamen length in concert, but we also saw QTLs with effects on one or the 
other trait (Fishman et al., 2002). However, we found no QTLs with positive effects on style length and negative effects on stamen length, which suggests that the genetic architecture of floral divergence between these species does not generally dictate negative pleiotropic associations between male and female organs. In contrast, the extreme male-sterile phenotype produced by CMS in hybrids clearly has strong positive effects of female organ size while having negative effects on corolla size. This is particularly striking in the context of other forms of male sterility in Mimulus hybrids. A nuclear Dobzhansky-Muller incompatibility causes complete pollen sterility (many unfilled pollen grains) in a fraction of $F_{2}$ hybrids between the same parental lines (Fishman and Willis, 2001; Sweigart et al., 2006). However, in this case, maximum seed set was also greatly reduced in male steriles (Sweigart et al., 2006), causing positive correlations between male and female fertility (Fishman and Willis, 2001). Overall, these results suggest that the positive pleiotropic effects of CMS on female organs are in some way special or outside the normal pathways of floral development. This could be a necessary consequence of hormonal changes initiated by early anther loss or it could reflect a past history of selection for only those male-sterilizing mitochondrial mutations that have positive effects on allocation to female organs. The latter case is particularly consistent with an evolutionary scenario in which a novel sterile cytoplasm invaded the hermaphroditic Iron Mtn. population of M. guttatus, spread via intrinsic female fitness effects, then fixed in concert with nuclear restorer alleles. Further experimentation with M. guttatus-background NILs, as well as molecular population genetic data on the restorer loci, will be necessary to explicitly test this scenario.

Finally, although our data strongly suggest that the suite of floral changes associated with male sterility are direct pleiotropic effects of disrupted anther development, we cannot completely rule out effects of a few genes tightly linked to the restorer loci. Any linked locus, however, would have to be in the short region of potential line overlap (between markers 19145 and 14_172; Figure 1) to explain, for example, the changes in stigmatic exsertion seen in all lines. This region contains only 17 predicted open reading frames, of which 10 are $R f$-candidate PPR proteins, 5 are retrotransposons and the remaining 2 (a cysteine synthase and a stearoyl-acyl carrier protein) house the gene-based markers. Future positional cloning and transformation experiments focused on this region will provide the opportunity to parse out the effects of individual candidate PPRs and to confirm potential pleiotropic effects of CMS expression.

\section{Conflict of interest}

The authors declare no conflict of interest.

\section{Acknowledgements}

We gratefully acknowledge Carson Lindbeck, Jeff van Noppen and Carole Brabham for help with data collection; Ben Sundy, Chelsea Luce and Samantha Campbell for help with greenhouse care; and Elizabeth Crone for help with data analysis. We thank Dan Rokhsar and Jeremy Schmutz of DOE Joint Genome Institute for providing access to $M$. guttatus draft whole-genome sequence prior to public release. The manuscript benefited from comments from several anonymous reviewers. This work was supported by funding from the National Science Foundation (DEB-0316786, MRI grant DBI-0321329 and FIBR grant EF-0328636).

\section{References}

Anderson IA, Busch JW (2006). Relaxed pollinator-mediated selection weakens floral integration in self-compatible taxa of Leavenworthia (Brassicaceae) 93: 860-867.

Ashman T-L (1994). Reproductive allocation in hermaphrodite and female plants of Sidalcea oregana ssp. spicata (Malvaceae) using four currencies. Am J Bot 81: 433-438.

Ashman T-L, Majetic CJ (2006). Genetic constraints on floral evolution: a review and evaluation of patterns. Heredity 96: 343-352.

Ashman TL, Stanton M (1991). Seasonal variation in pollination dynamics of sexually dimorphic Sidalcea oregana spp. spicata (Malvaceae). Ecology 72: 993-1003.

Ashman T-L, Williams CF (2003). Constraints on the evolution of males and sexual dimorphism: field estimates of genetic architecture of reproductive traits in three populations of gynodioecious Fragaria virginiana. Evolution 57: 2012-2025.

Atlan A, Gouyon PH, Fournial T, Pomente D, Couvet D (1992). Sex allocation in an hermaphroditic plant-the case of gynodioecy in Thymus vulgaris L. J Evol Biol 5: 189-203.

Baker HG (1948). Corolla size in gynodioecious and gynomonoecious species of flowering plants. Proc Leeds Soc Sci Sect 5: 136-139.

Barr CM (2003). Sex Ratio Evolution in Nemophila menziesii. PhD Thesis, University of California: Irvine.

Barr CM (2004a). Hybridization and regional sex ratios in Nemophila menziesii. J Evol Biol 17: 786-794.

Barr CM (2004b). Soil moisture and sex ratio in a plant with nuclear-cytoplasmic sex inheritance. Proc $R$ Soc Lond Series B-Biol Sci 271: 1935-1939.

Barr CM, Fishman L (2010). The nuclear component of a cytonuclear hybrid incompatibility in Mimulus maps to a cluster of pentatricopeptide repeat (PPR) genes. Genetics 184: 455-465.

Bateman AJ (1948). Intra-sexual selection in Drosophila. Heredity 2: 349-368.

Bell G (1985). On the function of flowers. Proc $R$ Soc Lond Series B-Biol Sci 224: 223-265.

Budar F, Touzet P, De Paepe R (2003). The nucleo-mitochondrial conflict in cytoplasmic male sterilities revisited. Genetica 117: 3-16.

Burt A, Trivers R (2006). Genes in Conflict: The Biology of Selfish Genetic Elements. Harvard University Press: Cambridge.

Case AL, Willis JH (2008). Hybrid male sterility in Mimulus (Phrymaceae) is associated with a geographically restricted mitochondrial rearrangement. Evolution 62: 1026-1039.

Charlesworth B, Charlesworth D (1978). Model for the evolution of dioecy and gynodioecy. Am Nat 112: 975-997.

Charlesworth D, Ganders FR (1979). The population genetics of gynodioecy with cytoplasmic-genic male-sterility. Heredity 43: 213-218.

Conner J, Via S (1993). Patterns of phenotypic and genetic correlations among morphological and life-history traits in wild radish, Raphanus raphanistrum. Evolution 47: 704-711.

Conner JK (2002). Genetic mechanisms of floral trait correlations in a natural population. Nature 420: 407-410.

Conner JK, Sterling A (1995). Testing hypotheses of functional relationships: a comparative survey of correlation patterns among floral traits in five insect-pollinated plants. Am J Bot 82: 1399-1406.

Darwin CR (1877). The Different Forms of Flowers on Plants of the Same Species. J Murray: London. 
Delph LF, Galloway LF, Stanton ML (1996). Sexual dimorphism in flower size. Am Nat 148: 299-320.

Diaz A, MacNair MR (1998). The effect of plant size on the expression of cleistogamy in Mimulus nasutus. Funct Ecol 12: 92-98.

Eckhart VM (1999). Sexual dimorphism in flowers and inflorescences. MA Geber, TE Dawson and LF Delph (eds). Gender and Sexual Dimorphism in Flowering Plants. Springer: New York, 123-148.

Fishman L, Willis JH (2001). Evidence for Dobzhansky incompatibilities contributing to the sterility of hybrids between Mimulus guttatus and M. nasutus. Evolution 55: 1932-1942.

Fishman L, Kelly AJ, Willis JH (2002). Minor quantitative trait loci underlie floral traits associated with mating system divergence in Mimulus. Evolution 56: 2138-2155.

Fishman L, Willis JH (2006). A cytonuclear incompatibility causes anther sterility in Mimulus hybrids. Evolution 60: 1372-1381.

Fishman L, Willis JH (2008). Pollen limitation and natural selection on floral characters in the yellow monkeyflower Mimulus guttatus. New Phytol 177: 802-810.

Frank SA (1989). The evolutionary dynamics of cytoplasmic male sterility. Am Nat 133: 345-376.

Frank SA, Barr CM (2001). Spatial dynamics of cytoplasmic male sterility. J Silvertown and J Antonovics (eds). Integrating Ecology and Evolution in a Spatial Context. Cambridge University Press: Cambridge, 219-243.

Golonka AM, Sakai AK, Weller SG (2005). Wind pollination, sexual dimorphism, and changes in floral traits of Schiedea (Caryophyllaceae). Am J Bot 92: 1492-1502.

Hanson M, Bentolila S (2004). Interactions of mitochondrial and nuclear genes that affect male gametophyte development. Plant Cell 16: 154-169.

Johnson SG, Delph LF, Elderkin CL (1995). The effect of petal size manipulation on pollen removal, seed set, and insect-visitor behavior in Campanula americana. Oecologia 102: 174-179.

Kaneko M, Itoh H, Inukai Y, Sakamoto T, Ueguchi-Tanaka M, Ashikari M, Matsuoka M (2003). Where do gibberellin biosynthesis and gibberellin signaling occur in rice plants? Plant J 35: 104-115.
Krizek BA, Fletcher JC (2005). Molecular mechanisms of flower development: an armchair guide. Nat Rev Genet 6: 688-698.

Kudoh H, Sugawara T, Wu SG, Murata J (2001). Morph-specific correlations between floral traits in a distylous Ophiorrhiza napoensis (Rubiaceae) population in southern China. J Trop Ecol 17: 719-728.

Lloyd DG, Webb CJ (1977). Secondary sex characters in plants. Bot Rev 43: 177-216.

Manicacci D, Atlan A, Rossello JAE, Couvet D (1998). Gynodioecy and reproductive trait variation in three Thymus species (Lamiaceae). Int J Plant Sci 159: 948-957.

Meagher TR (2007). Linking the evolution of gender variation to floral development. Ann Bot 100: 165-176.

Plack A (1957). Sexual dimorphism in Labiatae. Nature 180: 1218-1219.

Raab MM, Koning RE (1988). How is floral expansion regulated-a variety of plant regulators control growth of flower organs, which interact sequentially. Bioscience 38: 670-674.

Schultz ST (2003). Sexual dimorphism in gynodioecious Sidalcea hirtipes (Malvaceae). II. Floral traits. Int J Plant Sci 164: 175-180.

Shykoff JA, Kolokotronis S-O, Collin CL, Lopez-Villavicencio M 2003. Effects of male sterility on reproductive traits in gynodioecious plants: a meta-analysis. Oecologia 135: 1-9.

Stanton ML, Preston RE (1988). Ecological consequences and phenotypic correlates of petal size variation in wild radish, Raphanus sativus (Brassicaceae). Am J Bot 75: 528-539.

Sweigart AL, Fishman L, Willis JH (2006). A simple genetic incompatibility causes hybrid male sterility in Mimulus. Genetics 172: 2465-2479.

Thompson JD, Rolland AG, Prugnolle F (2002). Genetic variation for sexual dimorphism in flower size within and between populations of gynodioecious Thymus vulgaris. J Evol Biol 15: 362-372.

Van Damme JMM, Van Delden W (1984). Gynodioecy in Plantago lanceolata L. IV. Fitness components of sex types in different life cycle stages. Evolution 38: 1326-1336.

Widen M, Widen B (1999). Sex expression in the clonal gynodioecious herb Glechoma hederacea (Lamiaceae). Can J Bot 77: 1689-1698.

Zubko MK, Zubko EI, Adler K, Grimm B, Gleba YY (2003). New CMS-associated phenotypes in cybrids Nicotiana tabacum L. (Hyoscyamus niger L.). Ann Bot 92: 281-288. 